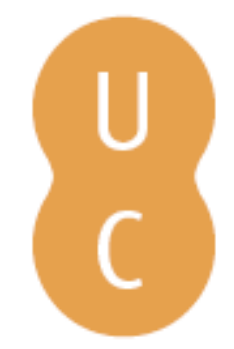

\title{
pommalina
}

\section{Ars retórica/ars teatral y el decorum como factor de escritura: una traducción argentina de Miles Gloriosus para la escena}
Autor(es):
Pricco, Aldo Rubén
Publicado por: $\quad$ Centro de Estudos Clássicos e Humanísticos da Universidade de
Coimbra; Imprensa da Universidade de Coimbra URL persistente:
DOI: $\quad$ DOI:http://dx.doi.org/10.14195/978-989-721-038-9_47
Accessed : $\quad$ 26-Apr-2023 03:21:16

A navegação consulta e descarregamento dos títulos inseridos nas Bibliotecas Digitais UC Digitalis, UC Pombalina e UC Impactum, pressupõem a aceitação plena e sem reservas dos Termos e Condições de Uso destas Bibliotecas Digitais, disponíveis em https://digitalis.uc.pt/pt-pt/termos.

Conforme exposto nos referidos Termos e Condições de Uso, o descarregamento de títulos de acesso restrito requer uma licença válida de autorização devendo o utilizador aceder ao(s) documento(s) a partir de um endereço de IP da instituição detentora da supramencionada licença.

Ao utilizador é apenas permitido o descarregamento para uso pessoal, pelo que o emprego do(s) título(s) descarregado(s) para outro fim, designadamente comercial, carece de autorização do respetivo autor ou editor da obra.

Na medida em que todas as obras da UC Digitalis se encontram protegidas pelo Código do Direito de Autor e Direitos Conexos e demais legislação aplicável, toda a cópia, parcial ou total, deste documento, nos casos em que é legalmente admitida, deverá conter ou fazer-se acompanhar por este aviso.

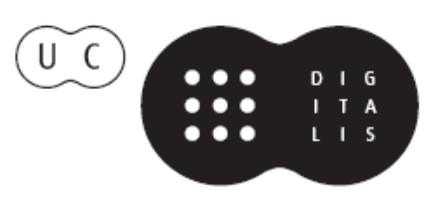




\section{De ayer a hoy}

\section{Influencias clásicas en la literatura}

\section{Aurora López, Andrés Pociña, Maria de Fátima Silva (coords.)}




\title{
$A R S$ RETórica / $A R S$ TEATRAL Y EL DECORUM COMO FACTOR DE ESCRITURA: UNA TRADUCCIÓN ARGENTINA DE MILES GLORIOSUS PARA LA ESCENA ${ }^{I}$
}

Aldo Rubén Pricco Universidad Nacional de Rosario

\begin{abstract}
La ars retórica y la teatral dotan al programa del teatro de Plauto de una plataforma retórica/metateatral/ficcional que construye su auditorio en la medida que, por decorum, releva del colectivo romano doxas y representaciones de los imaginarios, instituye verosímiles e instaura, a la vez, procedimientos de seducción espectacular para su consumo. Este trabajo propone, desde ese presupuesto, una muestra de criterios de traducción-adecuación retórica del discurso plautino y orientaciones de reposición en términos actuales de nomina, dicta y referencias contextuales que operen en el convivium de un modo humorístico supuestamente similar al de la "relación teatral" de la república romana.
\end{abstract}

El complejo fenómeno de la traducción de textos teatrales puede ser asistido por la teoría retórica en tanto se considere la escritura dramatúrgica una práctica enunciativa destinada a transformar al destinatario. En ese sentido, en la tradición retórica latina posterior a la producción plautina (Cicerón, Quintiliano) se observa la insistencia en el hecho de la inexistencia de un auditorio universal, lo que implica para el orador -homologamos ese artífice al dramaturgo y/o al dominus gregis- dar cuenta de un saber concreto, el que proviene del conocimiento de las doxas circulantes, los intereses de clase, los contextos, las procedencias, las idiosincrasias, los gustos y hábitos de una audiencia particular. Sostenemos que en la palliata plautina, a partir de la ars retórica en conjunción con la teatral, emerge la necesidad de fijar el territorio de lo proyectable, los límites y formas de lo legible y aceptable para una audiencia-videncia. Se trataría de una construcción retórica que recoge del colectivo romano intereses, necesidades, e instituye verosímiles, habitualidades y tendencias estéticas.

Si se adscribe a la concepción de teatralidad de triple acontecimiento (convivial, poético y de expectación) según Dubatti (2003), podemos postular

\footnotetext{
${ }^{1}$ Se hace referencia a la traducción de Aldo Pricco (1998) que obtuviera el Premio Teatro del Mundo a la traducción 2006 otorgado por el Área de Historia y Teoría Teatral del Centro Cultural Ricardo Rojas de la Universidad de Buenos Aires y que fuera estrenada por el "Teatro de la Universidad", elenco oficial de la UNR, en la ciudad de Rosario, en ocasión del "XIX Simposio Nacional de Estudios Clásicos" organizado por las Universidades Nacionales de La Plata y Rosario, Argentina (2006) y mantenida en cartel en varias ciudades de Argentina hasta 2010.
} 
la índole de "programa" del teatro de Plauto, consistente en una plataforma retórica/metateatral/ficcional que alimenta la hipótesis de una dramaturgia que construye su auditorio en la medida que, por decorum ${ }^{2}$, releva doxas y representaciones de los imaginarios, e instaura, a la vez, procedimientos de seducción espectacular para su consumo. Esto nos conduce a una traducción del corpus de Plauto que hipotetiza sobre intereses contemporáneos a partir de los cuales se estaría en condiciones de reponer en términos actuales nomina, dicta y referencias contextuales en virtud de las cuales se operaría en el convivium de un modo supuestamente similar al de la "relación teatral" de la república romana.

Desde la perspectiva lingüística se ha asistido comúnmente a la presencia de una doxa del lenguaje "clásico", consistente -en sus versiones más difundidas- en construcciones ricas en léxico, provistas de procedimientos tales como el hipérbaton y un trato coloquial entre los personajes que inscribían el intercambio parlamentario en complicaciones de lo literario por sobre lo pragmático de la escena. En tal sentido la traducción de lo clásico, por pretendidas e discrecionales "purezas", no resultaron habilitadas para el voseo argentino o la recurrencia a léxico, sintaxis y morfología rioplatenses capaces de permitir desde lo fónico un margen lúdico considerable más allá de lo estrictamente semántico. El paradigma español peninsular, en cambio, parecía proveer de matrices institucionalizadas para una adecuación correcta a los fines "clásicos".

La búsqueda de una especificidad lingüística puede facilitar el consumo del componente fónico si la cultura teatral de destino es la argentina, lo que orienta hacia tácticas de verosimilización que incluyan el oído medio del espectador de nuestro país como variable de diseño de una traducción. De allí la inclusión en nuestra traducción de diversas formas del voseo, incluso con su variante regional litoral que registra caídas de sibilantes y vibrantes finales, como así también modelos de ideologemas frecuentes en el discurso de los medios.

Una nota pertinente de la adecuación a cierta coyuntura histórica que permite un símil del militar presuntuoso resulta la puesta en boca del personaje miles de las frases "Un soldado no duda, acciona. La duda es la jactancia de los intelectuales”. Esta alocución, textual, pertenece al entonces teniente Aldo Rico, militar "carapintada" alzado en armas contra la democracia argentina

\footnotetext{
${ }^{2}$ Aunque en sentido general decorum refiera a la "conveniencia", "decoro", "armonía”, en términos de retórica se ajusta a la adecuación entre el dictum y lo que se supone pretende oír (o reaccionar) un interlocutor. Esta conveniencia se desprende del sentido común y de las convenciones de adecuación. No tiene un sentido natural estricto sino eminentemente cultural y fijado, por ende, por las tradiciones. Pueden sumarse mecanismos fisiológicos de la percepción. Cf. Quint., Inst. Orat., X, 1, 17; XI, 1, 4; XI, 3, 150-154, 177.
} 
por segunda vez en enero de 1988 en Monte Caseros, provincia de Corrientes. Tristemente célebre, el movimiento fue uno de los últimos intentos de golpe de estado sufridos por la institucionalidad en la República Argentina y, a la distancia, el episodio discursivo del jefe castrense rendido se aviene a revestir los atributos del fanfarrón plautino.

Tener especialmente en cuenta la etimología de los nombres de los personajes ha resultado otra herramienta que, en virtud de la ratio pocas veces atendida, además de recuperar la vinculación entre máscara y espectadores, opera como un pulso de recuerdo de las condiciones cómicas del personaje. Así, el criterio ha oscilado entre la traducción que reelabora semas y otra que se monta sobre semejanzas de sonoridad. A modo de síntesis entre las dos alternativas el nomen del soldado de Miles gloriosus, Pyrgopolynices, ha sido repuesto como "Virgopolinízame", en abierto juego irónico sexual. El parásito, en cambio, remite a su pasión ingestiva con el simple "Hartotragón" que parte de Artotrogus. En este panorama de nomina, el del servus Sceledrus se aviene a una adecuación a la conducta un tanto pusilánime la asignación de "Estelerdo", que recuerda en cada apelación su condición y sirve para que los actores pronuncien el nombre a manera de burla, como una acción que degrada el rol y lo ubica en la inferioridad necesaria para la distancia cómica.

El caso de las prostitutas comporta, asimismo, un juego semántico: Acroteleutium, está "en la punta" y es, por eso, en nuestra versión, "La Top", en un guiño abiertamente popular de reconocimiento jerárquico de su profesión, mientras que su acompañante y gran hacedora de la fabula, Milphidippa, obtiene, literalmente y por metonimia, el nombre de "Parpadocaído", un signo de lo avanzado de una enfermedad venérea. El semisenex Periplectomenus recibe el nombre de "Enredado", tanto por su implicación en el engaño como por su abierta colaboración con el adulescens Pleusicles, quien de "ilustre navegante" pasa a nuestra traslación como "Ágilmarino", un apelativo que en la dinámica actoral sirve para desplegar juegos de palabras y, a la vez, habilitar ciertas burlas con el adjetivo "gil", que remite a "tonto", una condición asociada al enamoramiento del joven y ciertas torpezas de su accionar. Al mismo tiempo hemos seleccionado "Malabar" para Palaestrio por considerar que la habilidad - característica de un malabarista- para resolver cada imprevisto es clave en su comportamiento, a la vez que el ambiguo "Fiestera" para un hablante argentino -con notas inequívocas de prácticas sexuales promiscuas y colectivas- recoge para nosotros, con cierta hipérbole, el "amor por los banquetes" de Philocomasium, la amante del joven y concubina del miles.

Como se puede apreciar, una adecuación a verosímiles que no dependan de una tradición de lectura sino de una inmediata correspondencia entre apelación, sonoridad y conducta pueden hacerse cargo por decorum de un pasaje a la lengua de destino. Incluso esos nomina, en la puesta en escena, no 
sólo remiten a una persona sino que, una vez mencionados, activan efectos en nombradores y nombrados.

Ciertas referencias de batallas inexistentes que el parasitus lleva a cabo en su ardua labor de obsecuencia por lograr un bocado han sido modificadas en virtud de fraseos conocidos por el espectador. Tal es el caso de los versos 13-15 referidos a los "campos Curculionenses", (Quemne ego servavi in campis Curculioniis, / ubi Bumbomachides Clutomistaridysarchides / erat imperator summus, Neptun nepos?), que preferimos traducir y procesar como " ¿Cuando el Supremo tenía el mando en la batalla de Rajandoquevienepapá?”, dado que se conserva la composición una palabra extensa que, por otra parte, sintetiza la jactancia del militar mediante una locución popular argentina.

En el mismo plano léxico, cada vez que algún personaje se refiere a la pretendida belleza del soldado fanfarrón en vez de hacerlo con "hermoso" utiliza "harmoso", con la vocal "a", al modo de un reconocido personaje popular de televisión, "La Chona”, de las décadas del'60 y'70 interpretado por Haydée Padilla que quedó convertido en un decir extendido. La invitación del esclavo "Malabar" a "Estelerdo" del verso 335 (vin iam faciam, ut stultividum) “QQuerés que te obligue a admitir que sufrís de alucinaciones?” repone el adjetivo stultividum como "boludivisual" y se pretende hacer rendir así un adjetivo (y vocativo de variada índole) de amplio espectro en el uso coloquial argentino. Esta misma máscara, antes de ser expuesta a la farsa de la aparición de "Fiestera" por una de las casas, expone su misión de cuidar la castidad de la muchacha con cadencia de rap, para lo cual el texto se adapta rítmicamente (vs 344-353). Cuando la "gemela" hace su aparición, el perplejo servus intenta retenerla y reconducirla a la casa de su amo el militar (vs.449-452) enunciando un dictum reconocible de Juan Carlos Altavista, otro cómico popular argentino: "Fiestera: ¿Me soltás o no me soltás? Estelerdo: Efectivamente, todo lo contrario".

La hipótesis de estos usos alternativos, que desde un punto de vista filológico parecen no cubrir las correspondencias biunívocas requeridas por algunas posturas sobre la operación de traducción, consiste en que el reservorio léxico, musical, histórico, etc., oficia de resonancia en la memoria del colectivo público capaz de activar el mecanismo cómico por contigüidad o parodia. Se trata de la utilización de parte de una tradición por otra: si la palliata, en su compleja constitución, subsume modalidades más propias de la oralidad que de la escritura a los efectos de una verosimilitud lindante con el simulacro de la improvisación, el componente intertextual -presente en la memoria y los imaginarios- se presta a la complicidad entre los loci del texto de origen y la versión de destino. Los puentes entre ambas culturas resultan dicta sometidos a consumos y dispositivos semejantes. Nos referimos aquí a la tensión entre 
escritura e improvisación del juego teatral ${ }^{3}$ que intenta dotar de "espontaneidad" los parlamentos e interacciones dado que tanto la selección léxica como los préstamos de un decir contemporáneo se originan en ese intento de adaptar la dramaturgia a las condiciones de enunciación, y, particularmente, a los destinatarios.

Como es claro, la traducción de Miles gloriosus que motiva estas consideraciones, no obedece a un orden estrictamente literario sino escénico. Ha sido, justamente, la performance teatral la que ha facultado la textualidad para constatar su funcionamiento en la relación scaena/cavea actual. Esa confrontación ha puesto de manifiesto la complementación entre parlamentos y rutinas actorales vinculadas a dinámicas de clown y estética de cine mudo de principios del siglo XX, conforme a una tradición europea de varieté $\mathrm{y}$ especies dramáticas circenses y populares. Es en esa coreografía teatral en la que el texto plautino, liberado de la carga de doxas clásicas, ha planteado un diálogo efectivo con el espectador. Pueden mencionarse apelaciones a aplausos, pedidos de intervenciones directas al público, solicitudes de cantos corales entre espectadores e intérpretes, rupturas de la fictio plautina ${ }^{4}$ de plena técnica brechtiana, recurrencia a ritmos inscriptos en música de circulación marginal ${ }^{5}$ y soportes gestuales de actores y actrices cómicas argentinas de extenso repertorio que han pasado a formar parte del canon humorístico rioplatense del siglo XX: Los Cinco Grandes del Buen Humor (Jorge Luz, Rafael "Pato" Carret, Zelmar Gueñol, El Flaco García Cambón, Guillermo Rico), Niní Marshall, Pepe Iglesias (El Zorro), Dringue Farías, Nelly Láinez, Pepe Biondi, José Pepitito Marrone, Alberto Olmedo, Juan Carlos "Minguito" Altavista, Carlitos Balá, Tato Bores, Jorge Guinzburg y tantos otros que instauraron en la ficción hilarante modalidades discursivas y protocolos lúdicos quinésicos y gestuales que se extendieron rápida y festivamente a los intercambios sociales cotidianos urbanos.

Es, justamente, esa base de relevamiento de decires relativos a hábitos de humor la que a modo de hipótesis influyó en estrategias de compositio y elocutio dramatúrgica en la traducción de Miles gloriosus. Si uno de los componentes técnicos fundamentales de la escritura plautina resulta el montaje de las atracciones -en términos de Eisenstein ${ }^{6}$ el texto dramático argentino deviene

\footnotetext{
${ }^{3}$ Cf. Slater (1987: 143-146).

${ }^{4}$ Como homenaje, incluso, a rutinas teatrales de los Hermanos Marx y las televisivas de The Three Stooges.

${ }^{5} \mathrm{El}$ caso de la cumbia villera, popular en sectores carenciados de la sociedad argentina y luego extendida a otros grupos sociales, sobre todo de amplia presencia en los medios, es utilizado como formato musical del texto de Plauto para profundizar las marcas del estereotipo y establecer de esa manera el extremo artificio del recurso.

${ }^{6}$ La problemática de la acción eficaz en el teatro, entendida ésta como una manipulación perceptiva, sinestésica, cinestésica y cenestésica del espectador, ha sido probablemente el motor que
} 
objeto para la fijación de prescripciones que tienden a manipular el tiempo futuro del convivium conforme al estímulo constante de la percepción del espectador. Por ello, es frecuente en la comedia de Plauto en general y en El Soldado fanfarrón en particular la táctica constante de la apelación -o sus amagos- a la intervención del público, un dispositivo que sigue la línea de la mayoría de los cómicos mencionados. Nos referimos a que los enunciados plautinos se reservan una gran cuota de manipulación del orden perceptual basándose en la "inclusión" del público en los imponderables de la tradición de la que forma parte. Se trataría de un acontecimiento de efectos de participación cuyo mecanismo reside en la incorporación del espectador en los enunciados, tanto explícitamente en el uso pronominal de un simulacro de interacción dialógica como en la "actuación en citas"7 que se desprende del corpus parlamentario de la obra plautina.

desde la práctica concreta ha concretado los carriles estructurales de muchísimas dramaturgias. Sin embargo, el formato de una especulación teórica específica acerca de la cuestión, ya instalada en el ámbito de las artes audiovisuales y no sólo en la retórica, aparece con fuerza e identidad durante el siglo pasado en las reflexiones de Eisenstein. Es a partir de la puesta en escena de espectáculos teatrales (que luego serán traspoladas al cine) que el director ruso desarrolla una serie de teorizaciones que convergen en un cuerpo conformado por escritos sobre las obras "El mexicano" (1921) y "El ensayo" (1923). Los dos textos fundamentales (1923) se vinculan mayormente con "El ensayo" y revisten el carácter de, prácticamente, un manifiesto programático denominado El montaje de las atracciones. Se trata de una escritura que, encabalgada entre la práctica concreta y la reflexión, indaga acerca de las atracciones y los movimientos expresivos, un territorio aparentemente reservado a la disciplina retórica y, sobre todo, a la instancia actio. Se trata de llevar a un primer plano de las preocupaciones del discurso escénico el diseño de la reacción psicofísica del espectador. El sostenimiento de la teatralidad halla así la inevitabilidad de habilitar una maquinaria de manipulación: el espectador es puesto en la condición de material fundamental del teatro; modelar al espectador según una tendencia (disposición de ánimo) deseada es la tarea de cualquier teatro utilitario (propaganda, publicidad, instrucción sanitaria). Este proceso de modelado, que supone desde el conocimiento retórico un saber del destinatario y su contexto, se apoya en elementos verbales y no verbales del espectáculo a los que Eisenstein denomina "atracciones": la atracción (desde el punto de vista del teatro) es cualquier momento agresivo del teatro, es decir, cualquiera de sus elementos que ejerza sobre el espectador un efecto sensorial o psicológico, verificado experimentalmente y calculado matemáticamente, de modo tal de producir determinados estremecimientos emotivos, los cuales, a su vez, todos juntos, determinan en quien percibe la condición para receptar el lado ideal y la conclusión ideológica a la que tiende el espectáculo. La atracción es un elemento autónomo y primario de la construcción del espectáculo: la unidad molecular, es decir, constitutiva de la eficiencia del teatro y del teatro en general. Este punto de vista, que entiende el espectador como ámbito y objeto de trabajo dramatúrgico, como entidad psicofísica sobre la cual orientar desde la textualidad y su actualización en el espacio-tiempo estímulos concretos para provocar reacciones y organizar -mínimamente- sensaciones, se enlaza, a su vez, con el correlato escénico: el actor. Cf. Eisenstein (1986)

7 De Toro, al caracterizar una hipótesis de actuación distanciada, inherente al posible modelo brechtiano, menciona esta noción que nos parece adecuada a la tipología de la masa parlamentaria plautina, dominada por la melodía, el ritmo y la música. Una "actuación en citas" requeriría del sujeto parlante una distancia respecto de su decir, una apropiación en segundo término que expone la exterioridad de la autoría de su discurso. El acontecimiento recupera de esa manera su status de "mostración" y el texto verbal se aproxima a la "demostración" (1987: 30). 
En efecto, siguiendo estos criterios, el receptor de la obra no parte de cero sino que es consciente de que está en una situación que lo envuelve en el seno de la tradición. La aceptación de tal situación no es un defecto de su capacidad de reflexión, sino la realidad histórica misma que lo define. A esa situación le corresponde evidentemente un cierto horizonte que puede estrecharse o ampliarse, pero que, sobre todo, le permite situar las cosas en su ámbito. El estado de recepción, tanto el percibido por el autor de las comedias a través de su inserción social, como el imaginado, proyectado y diseñado en la escritura, incide de manera relevante en la decisión de contenidos y formatos que, de ese modo se alejan de perspectivas de análisis sólo literarios. En ese sentido, el objeto de estudio no se clausura en el texto dramático, dado que se constituye progresivamente desde su carácter de incompletitud en la actividad del espectador, quien completa y actualiza las potencialidades significativas y comunicativas de la obra. Los enunciados plautinos no son una entidad acabada y cerrada en sí misma sino que adquieren sentido como hecho estético y semiótico en referencia a los momentos de producción y recepción. Es allí la "relación teatral" la categoría que nuclea el análisis del fenómeno y consiste, justamente, en una manipulación del espectador de parte del espectáculo: mediante su acción o puesta en acto de determinadas estrategias seductivo-persuasivas, la dinámica escénica trata de inducir en el espectador determinadas transformaciones intelectuales y pasionales (ideas, creencias, valores, emociones, fantasías, etc.).

Esta dimensión manipulatoria del espectáculo (De Marinis, 2005: 117118) se puede articular en los términos de la teoría semiótica de Greimas en tanto la "relación teatral" - decorum mediante- no consiste sólo en un saberhacer (una transferencia de informaciones, significados, conocimientos) sino también y en mayor medida en un hacer-creer y en un hacer-hacer tendientes a inducir en el espectador, respectivamente, un deber/querer-creer y un deber/ querer-hacer (Greimas-Courtés, 1979: 206-208).

Los itinerarios receptivos de la textualidad de Miles gloriosus se afincan en tradiciones, competencias y habitualidades de rigurosa repetición, a través de formatos y tópicos preestablecidos y conocidos de antemano. En ese sentido, la cultura de destino de una traducción ejerce presiones que atraviesan la neutralidad de una versión filológica y sólo anotada para modelar un texto otro (como toda traductio) que en su índole poética interactúa con interlocutores que el artefacto escénico -como la máquina retórica- debe docere, delectare, persuadere a los efectos de que integren el convivium y le otorguen legitimidad y existencia al mismo acontecimiento teatral.

Este trabajo propone, en síntesis, una muestra de criterios de traducciónadecuación retórica del discurso plautino que, sometida a la confrontación escena/público, ha obtenido una respuesta eficaz en términos pragmáticos 
Aldo Rubén Pricco

y ha permitido constatar -atravesando cánones- continuidades de ciertas tradiciones cómicas en el ajuste retórico de formatos y estereotipos. 


\section{BibLiográfia}

Arnheim, R. (2001), Arte y Percepción visual, Madrid, Alianza. (1985), El pensamiento visual, Buenos Aires, Eudeba.

Bajtin, M. (2002), Estética de la creación verbal, Buenos Aires, Siglo Veintiuno Editores.

Barba, E. y Savarese. N. (1990), El arte secreto del actor, México, EscenologíaUNAM.

Barchiesi, M. (1969), "Plauto e il metateatro antico", Il Verri 31, 113-130.

Beacham, R. C. (1991), The Roman Theatre and its Audience, Cambridge, Harvard University Press.

Beare, W. (1972), La escena romana, Buenos Aires, Eudeba. (1928), "Plautus and his public", CR 42, 106-111.

Brecht, B. (1970), Escritos sobre teatro, Buenos Aires, Nueva Visión.

Calvarese, O. (1998), "Postfazione. Il teatro del corpo estatico", en Eisenstein, S. M., Il movimento espressivo. Scritti sul teatro, (249-264) al cuidado de Montani, P., Venezia, Marsilio.

Castoriadis, C. (1993), La institución imaginaria de la Sociedad, Buenos Aires, Tusquets.

Chalmers, W. R. (1965), "Plautus and his Audience", En T. A. Dorey et R. Dudley (eds.), Roman Drama, London, Routledge.

De Marinis, M. (2005), En busca del actor y del espectador. Comprender el teatro II, Buenos Aires, Galerna. (1997), Comprender el teatro. Lineamientos de una nueva teatrología, Buenos Aires, Galerna.

De Toro, F., (1987), Brecht en el teatro hispanoamericano contemporáneo, Buenos Aires, Galerna.

Dubatti, J. (2008), Cartografía Teatral. Introducción al Teatro Comparado, Buenos Aires, Atuel.

(2007), Filosofía del Teatro I. Convivio, experiencia, subjetividad, Buenos Aires, Atuel.

(2003), El convivio teatral. Teoría y práctica del Teatro Comparado, Buenos Aires, Atuel.

(2002), El teatro jeroglifico. Herramientas de poética teatral, Buenos Aires, Atuel. 
Duckworth, G. (1952), The Nature of Roman Comedy. A Study in Popular Entertainment, New Jersey, Princeton.

Ehrenzweig, A. (1976), Psicoanálisis de la percepción artística, Barcelona, G. Gili. Eisenstein, S. (2001), Hacia una teoría del montaje. Vol. 1, Edición a cargo de Michael Glenny y Richard Taylor, Barcelona, Paidós.

(1986), "Il montaggio delle attrazioni", en "Il montaggio", Opere scelte, al cuidado de Montani, P., Venezia, Marsilio.

Féral, J. (2003), Acerca de la teatralidad, Buenos Aires, en Cuadernos de Teatro XXI, FFyL-UBA, Nueva Generación.

Greimas, A. J. (1983), La semiótica del texto, Barcelona, Paidos. (1966), Semántica estructural, Madrid, Gredos.

Greimas, A. J. y Courtés, J. (1991), Semiótica. Diccionario razonado de la teoría del lenguaje, Madrid, Gredos.

López, A. y Pociña, A. (2007), Comedia romana, Madrid, Akal.

Moore, T. (1998), The Theater of Plautus. Playing to the Audience, Austin University of Texas Press.

Pavis, P.(2000), El análisis de los espectáculos. Teatro, mimo, danza, cine, Barcelona, Paidós.

Perelman, C. y Olbrecht-Tyteca, I. (1994), La Nueva Retórica. Tratado de la Argumentación, Madrid, Gredos.

Pociña, A. y Rabaza, B. (eds.), Estudios sobre Plauto, Madrid, Clásicas.

Pricco, A. (2007), “Teatralidad cognitiva y teatralidad psicofísica en el discurso terenciano: la constitución del auditorio”, en Pociña, A., Rabaza, B., y Silva, M. F. (eds.), Estudios sobre Terencio, Granada, Universidad de Granada, pp. 357-371.

- (2005). "La dinámica entre escena y espectadores. Un caso de la comedia plautina", en Dubatti, J. (comp), Escritos sobre teatro I. Teatro y cultura viviente: Poéticas, Politica e Historicidad, Buenos Aires, Nueva Generación/CIHTT/Escuela de Espectadores, pp. 31-54..

Schechner, R. (2000), Performance, Teoría y prácticas interculturales, Buenos Aires, Libros del Rojas-UBA.

Selden, S. (1972), La escena en acción, Buenos Aires, Eudeba.

Slater, N. (1987), Plautus in Performance. The Theatre of the Mind, Princeton University Press.

Ubersfeld, A., Pavis P. et altri (1980), La relation téatrale (textes réunis par Regis Durand), Lille, Presses Universitaires. 